Bull. Mater. Sci., Vol. 21, No. 6, December 1998, pp. 469-474. (C Indian Academy of Sciences.

\title{
Effect of stoichiometry on the thermal expansion coefficients of lithium niobate single crystals
}

\author{
KAMAL SINGH*, P V SAODEKAR ${ }^{\dagger}$ and S S BHOGA ${ }^{\ddagger}$ \\ Department of Physics, Amravati University, Amravati 444 602, India \\ ${ }^{\dagger}$ Department of Physics, Jagadamba Mahavidyalaya, Achalpur 444806 , India \\ 'Department of Physics, Hislop College, Nagpur 440001 , India
}

MS received 2 March 1998; revised 20 August 1998

\begin{abstract}
The chemical analysis of $\mathrm{LiNbO}_{3}$ single crystals, with different melt compositions $(\dot{\mathrm{Li}} / \mathrm{Nb})_{m}=0.945$, 1.0, 1.1 and 1.2, grown by slow cooling technique, reveals a remarkable difference in solid and melt compositions. The thermal expansion coefficients along $a$ and $c$ axes, determined by using Newton's ring experiment, are found to increase anisotropically with increase in $(\mathrm{Li} / \mathrm{Nb})_{m}$ ratio. The variation in thermal expansion coefficient with increase in the $(\mathrm{Li} / \mathrm{Nb})_{m}$ ratio is discussed in the light of defect chemistry i.e the partial replacement of $\mathrm{Li}^{+}$by excess $\mathrm{Nb}^{5+}$ creates additional cation vacancies to attain the electro-neutrality in the crystal.
\end{abstract}

Keywords. Single crystal; thermal expansion; non-stoichiometry; defects; octahedra.

\section{Introduction}

Ferroelectric $\mathrm{LiNbO}_{3}$, hereafter abbreviated as $\mathrm{LN}$, is one of the most exciting materials in having a large electromechanical coupling constant, extremely small acoustic losses, optical transparency over a wide range of wavelength, and a very high Curie temperature $\left(1210^{\circ} \mathrm{C}\right)$. It has a number of technological applications viz. second harmonic generations (SHG), Q-switch, parametric oscillator, laser modulators and transducer (Boyd et al 1964; Kaminov and Turner 1966; Geusic et al 1968; Chen 1969).

The LN crystal at room temperature has rhombohedral structure with point group $3 m^{*}$ and space group $R 3 c$ (Abrahams et al 1966). It melts incongruently. Its structure and physical properties are dependent on the ratio of $\mathrm{Li}: \mathrm{Nb}$ (Rauber 1978). Also, doping of it with other cations drastically alters its physical properties.

Several defect models proposed to account for the deviation in $\mathrm{Li} / \mathrm{Nb}$ or metal/oxygen stoichiometry (Reisman and Holtzberg 1958; Shapiro et al 1964; Nassau et al 1966; Ohmachi et al 1967; Carruthers et al 1979; Singh and Deshmukh 1976; Singh and Tikkar 1986) have revealed that the defect concentration has a significant role to play beyond the congruent composition. Ballman and Gernand (1966) have suggested two major types of defects viz. oxygen vacancies and interstitial ions along with two electrons in one vacancy i.e. F2 centres in LN single crystal. Later, Lerner et al (1968)

*Author for correspondence introduced a concept of native atom in cationic sublattice on the basis of the following three assumptions: (i) niobium ions substituting to $\mathrm{Li}$ sites, (ii) lithium vacancies and (iii) interstitial niobium ions. According to him the first one is the most preferred one. On the other hand, Peterson and Carnevale (1972) have promoted the model with Li-vacancies. Nassau and Lines (1975) had suggested stacking fault model, which was well accepted earlier. However, recently a cation substitution model, proposed by Zotov et al (1994), describes, on the basis of fully occupied $\mathrm{Nb}$-sites and Li-site vacancies a best average structure which is substantiated by experimental evidences (combined neutron and X-ray diffraction).

While the dependence of properties such as dielectric, electrical conductivity, refractive indices and phase matching temperatures on stoichiometry of LN crystals have been studied extensively (Chung et al 1981; Volk 1984; Singh 1988), the investigation on its role in thermal expansion coefficients has been restricted only to the composition with $(\mathrm{Li} / \mathrm{Nb})_{m}=1$ (Abrahams et al 1966; Kim and Smith 1969; Smith and Welsh 1971). According to Abrahams et al (1966), the thermal expansion coefficient data is useful in revealing structural disorders. Further, a systematic study of the dependence of thermal expansion coefficients with the variation in the stoichiometry would be of importance due to its direct bearing on elastic and piezoelectric properties.

In the present paper, we report the thermal expansion coefficients (using indigenously developed experimental set up) along $a$ and $c$ axes on technologically important 
high-tech LN crystals with different melt compositions and grown by slow cooling of the melt.

\section{Experimental}

Lithium niobate single crystals, with four different melt compositions $(\mathrm{Li} / \mathrm{Nb})_{m}=0.945,1.0,1.1$ and 1.2 , were grown by slow cooling (Deshmukh and Singh 1972). The starting materials $\mathrm{Li}_{2} \mathrm{CO}_{3}$ and $\mathrm{Nb}_{2} \mathrm{O}_{5}$ were procured from Fluka AG, Germany. These were mixed in the above-mentioned stoichiometric proportion, ground and sintered for $12 \mathrm{~h}$ at $900^{\circ} \mathrm{C}$ in a platinum crucible. The temperature was steadily raised at the rate of $40^{\circ} \mathrm{C} / \mathrm{h}$ to $1300^{\circ} \mathrm{C}$ which is well above the melting point $\left(1253^{\circ} \mathrm{C}\right)$. After the melt had been kept at this temperature for $12 \mathrm{~h}$, it was cooled down at the rate of $5^{\circ} \mathrm{C} / \mathrm{h}$. At $1250^{\circ} \mathrm{C}$, a seed crystal of predetermined orientation was introduced in the melt and the slow rate of cooling maintained till it reached $1100^{\circ} \mathrm{C}$, which is below the eutectic temperature $\left(1160^{\circ} \mathrm{C}\right)$. The crystals thus obtained were annealed in atmospheric air at $1100^{\circ} \mathrm{C}$ for $12 \mathrm{~h}$, and subsequently the temperature was allowed to fall at a faster rate of $50^{\circ} \mathrm{C} / \mathrm{h}$. The prepared crystals of $\mathrm{Ln}$ were finally oriented by optical method and their faces were ground and polished to normal to the crystallographic $a$ and $c$ axes. The irregular shaped crystals were polished mechanically, and etched in one part of $\mathrm{HF}$ acid and two parts of $\mathrm{HNO}_{3}$ at boiling point of about $110^{\circ} \mathrm{C}$. The disturbed surfaces were then polished very rapidly. The crystals thus obtained were colourless, clear and transparent, with dimensions $1.5 \times 1 \times 0.5 \mathrm{~cm}^{3}$. The solid (final) compositions of each crystal $(\mathrm{Li} / \mathrm{Nb})_{c}$ were estimated by chemical analysis (atomic absorption spectroscopy, plane photometry) at the Institute of Chemistry, University of Uppsala, Sweden.

$\mathrm{X}$-ray diffraction (XRD) scans were recorded on powder of crushed and sieved single crystals with the help of PW $1700 \mathrm{X}$-ray powder diffractometer using $\mathrm{CuK} \alpha$ radiation at the scanning rate of $2 \theta=2.4 \% \mathrm{~min}$.

Thermal expansion coefficients along $a$ and $c$ axes of LN single crystals were determined by a home made Newton's ring assembly designed especially to give variation in temperature. Other than a heating assembly, part-8 of figure 1, which comprises of a brass disc of 2.5 and $3 \mathrm{~cm}$ diameter and thickness, respectively and is fitted on top of the rectangular fire brick block grooved precisely to fit a strip heater of dimension $4 \times 1 \times 0.2 \mathrm{~cm}^{3}$ in flat position on the top, the rest of the assembly was the usual Newton's ring assembly. The crystal was placed on the metal plate with its reflecting surface facing towards the lens.

During the measurements, at each set temperature, the crystal was allowed to attain thermal equilibrium for a dwell time of $900 \mathrm{~s}$. The temperature was measured with an accuracy of $\pm 0.5^{\circ} \mathrm{C}$ using pre-calibrated standard
Chromel-Alumel thermocouple. The temperature gradient within the sample may be neglected, since it is less than $0.5^{\circ} \mathrm{C} / \mathrm{mm}$, i.e. the instrumentation constant.

\subsection{Principle}

The thickness of the air film, enclosed by the lower surface of lens and upper surfaces of the crystal introduces the path difference between the rays reflected from these surfaces, in turn the interference. The air film thickness $d$ for dark ring (due to destructive interference) is:

$$
2 d=2 n \lambda / 2
$$

and $d^{\prime}$ for bright ring (due to constructive interference) is:

$$
2 d^{\prime}=(2 n+1) \lambda / 2
$$

Let $d_{1}$ be the air film thickness at $T_{1}$, thereby satisfying the condition for constructive/destructive interference, when the Newton's ring under consideration is bright/dark. The successive appearances of bright/dark ring are related with the change in air film thickness $d_{2}$ as a result of thermal expansion of the crystal. Thus

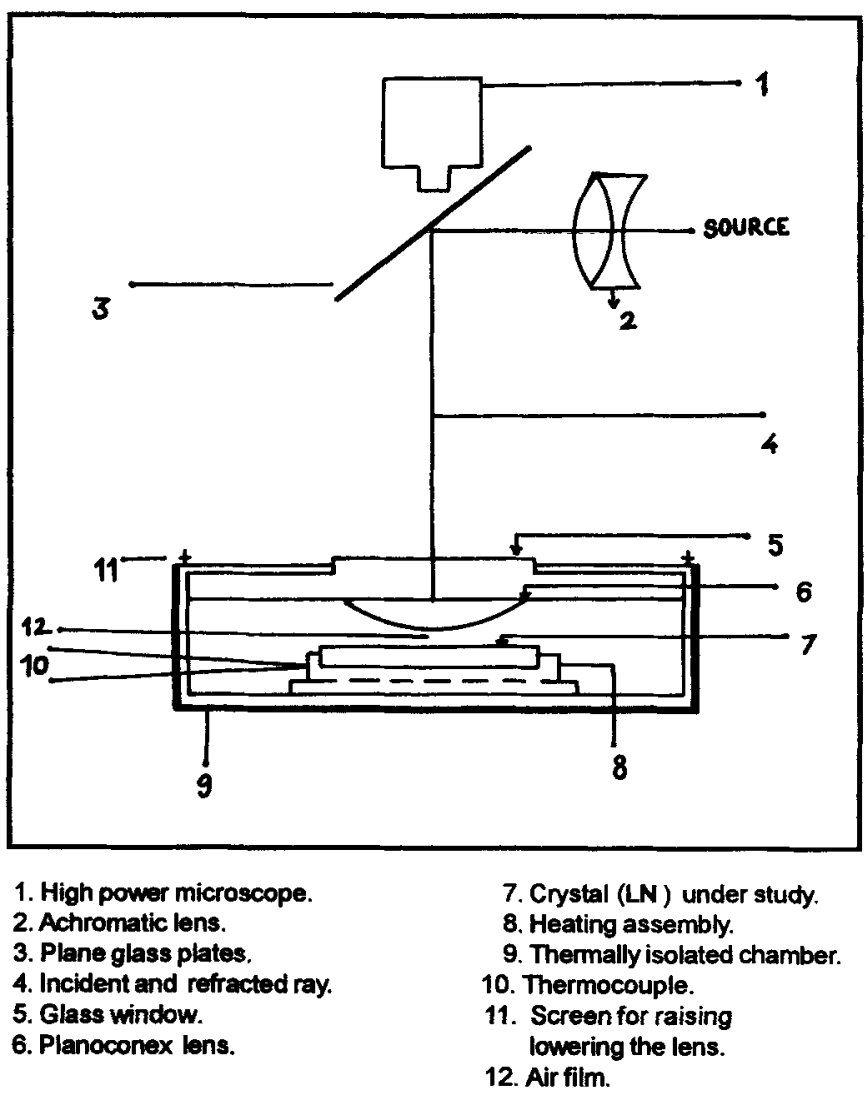

Figure 1. Newton's ring assembly for determination of thermal expansion coefficient. 


$$
\Delta d=d_{1}-d_{2}=x d / 2,
$$

where, $x$ is the number of times bright/dark ring appears, $d_{2}$ the air film thickness at temperature, $T_{2}$ and $\lambda$ the wavelength of light used. Accuracy in the measurement of change in the air film thickness, in turn its expansion, is $\lambda / 2$. The thermal expansion coefficient $\alpha$ is given by

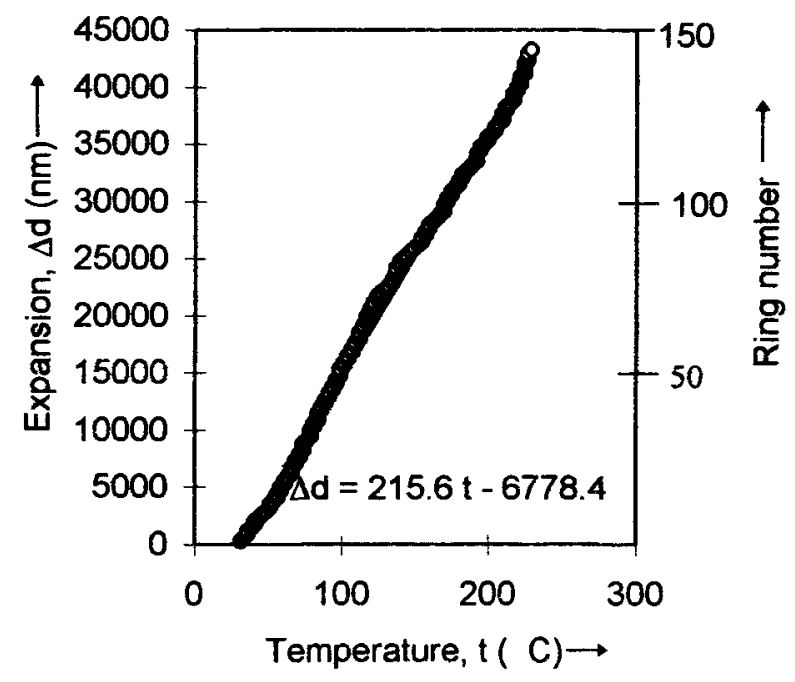

Figure 2. Calibration curve (expansion $(\Delta d)$ /number of rings vs temperature $(t)$ ); hollow circles $\rightarrow$ experimental data points; continuous line $\rightarrow$ after regression.

$$
\begin{aligned}
\alpha & =\frac{\Delta d}{l \Delta T}, \\
& =\frac{x \lambda}{2 l\left(T_{2}-T_{1}\right)},
\end{aligned}
$$

where $l$ is the thickness of the specimen.

Since we have used sodium vapour lamp, theoretical precision of the thermal expansion measurement is $294.5 \mathrm{~nm}$. The number of rings shifting across the cross wire was counted as a parametric function of temperature while heating and cooling, so as to determine the thermal expansion coefficients of the LN crystals, using the expression given in (4).

\subsection{Calibration}

A well-polished rectangular slab of silicon (single crystal) with dimensions $0.4 \times 0.4 \times 0.09 \mathrm{~cm}^{3}$ (prepared carefully) was used to calibrate/standardize the experimental setup. Figure 2 depicts the variation of sample thickness with temperature. The value of $\alpha\left(2.39 \times 10^{-6} /{ }^{\circ} \mathrm{C}\right)$ thus obtained following regression agrees with $2.3 \times 10^{-6} /{ }^{\circ} \mathrm{C}$, as reported by Lovell et al (1979).

\section{Results and discussion}

Figure 3 displays the diffractogram of $\mathrm{LN}$ crystal with $(\mathrm{Li} / \mathrm{Nb})_{m}=1.01$. All the experimental lines agree with the standard JCPDS data corresponding to LN, thereby indicating the absence of impurity precipitation. Single

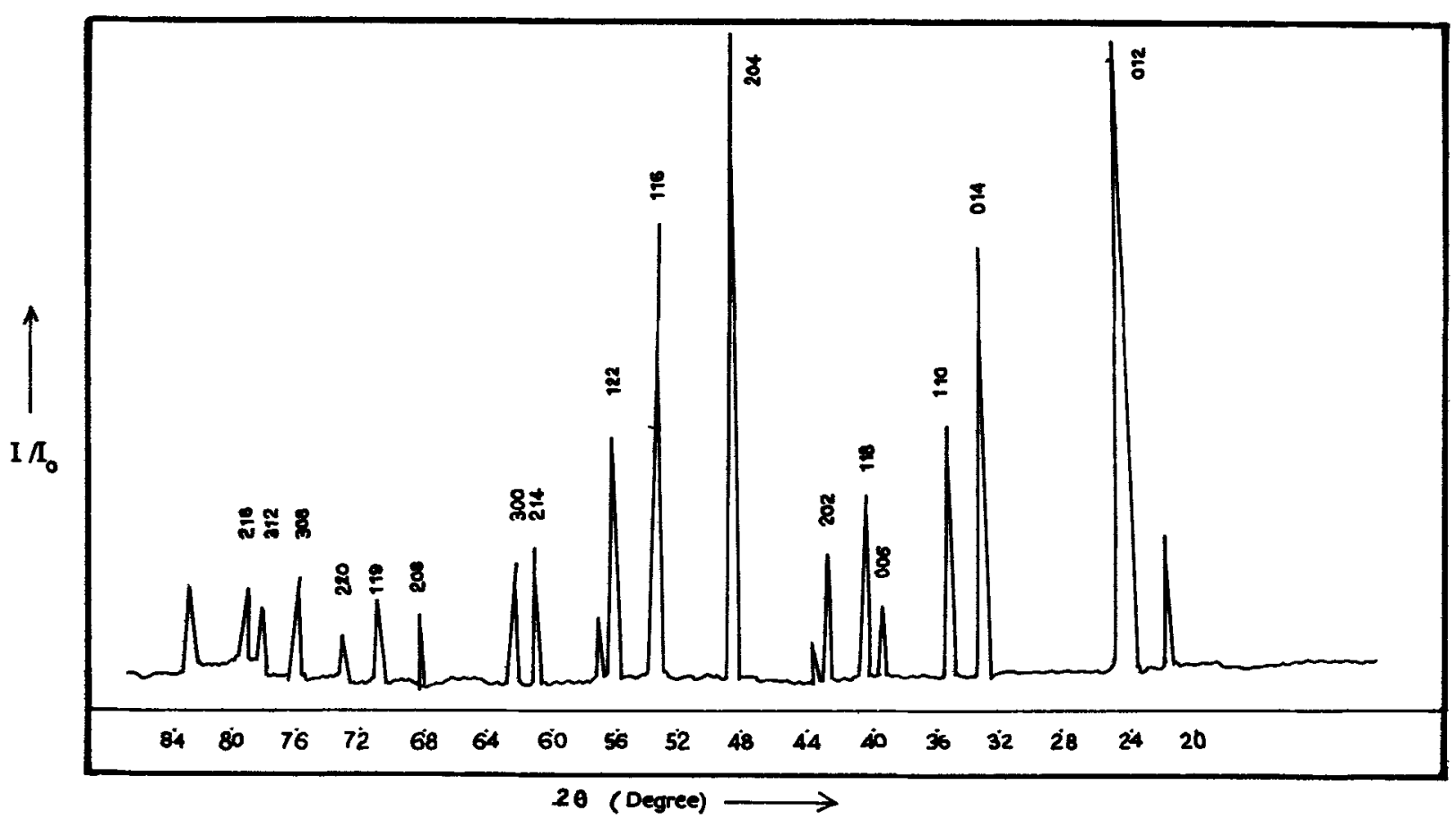

Figure 3. X-ray powder diffraction pattern of $\mathrm{LiNbO}_{3}$ 
crystal nature of each sample was confirmed by taking Laue pattern.

The chemical compositions of the crystal as determined by its chemical analysis are compared with the melt composition (table 1). Except for $48 \cdot 5 \mathrm{Li}_{2} \mathrm{O}: 51 \cdot 5 \mathrm{Nb}_{2} \mathrm{O}_{5}$, the crystal compositions of almost all the samples were observed to be different from that of the melt composition. Similar results have also been reported by Polgar et al (1979). The deviation in the crystal composition $(\mathrm{Li} / \mathrm{Nb})_{c}$ from the melt $(\mathrm{Li} / \mathrm{Nb})_{m}$, in general, is chiefly linked with the relative losses of $\mathrm{Li}_{2} \mathrm{O}$ and $\mathrm{Nb}_{2} \mathrm{O}_{5}$ individually and/or both during the crystal growth. Particularly, for higher content of $\mathrm{Li}_{2} \mathrm{O}$ in melt composition, its losses increase whereas, for lower content of $\mathrm{Li}_{2} \mathrm{O}$ in the melt composition, $\mathrm{Nb}_{2} \mathrm{O}_{5}$ losses dominate. At a critical composition $\left(48 \cdot 5 \mathrm{Li}_{2} \mathrm{O}: 51 \cdot 5 \mathrm{Nb}_{2} \mathrm{O}_{5}\right)$, possibly $\mathrm{Li}_{2} \mathrm{O}$ and $\mathrm{Nb}_{2} \mathrm{O}$ losses become quantitatively comparable. Thus, in the crystalline samples of many compounds nonstoichiometry is noticed, which is not so well understood from their phase diagrams.

$\mathrm{LN}$ is a nonstoichiometric compound and it forms a continuous solid solution $\mathrm{Li}_{2} \mathrm{O}-\mathrm{Nb}_{2} \mathrm{O}_{5}$ in the $\mathrm{Nb}$ rich side $\left(47-50 \mathrm{~mol} \% \mathrm{Li}_{2} \mathrm{O}\right)$. Lithium losses vis-à-vis increase in $\mathrm{Nb}^{5+}$ content lead to formation of solid solution. Since the ionjc sizes of $\mathrm{Li}^{+}(0.67 \AA)$ and $\mathrm{Nb}^{5+}(0.70 \AA)$ are comparable, partial substitution of the latter ion at lithium regular sites $\left(\mathrm{Nb}_{\mathrm{i} i \mathrm{i}}\right)$ is preferred rather than at interstitial sites $\left(\mathrm{Nb}_{\mathbf{i}} \cdots \cdot \cdot\right)$. Such partial substitution creates additional
$\mathrm{Li}^{+}$vacancies in the vicinity of $\mathrm{Nb}_{\mathrm{Li}}^{\cdots}$ so as to achieve the charge neutrality according to the formula,

$$
\begin{aligned}
& \quad\left[\mathrm{Li}_{1-5 x} \mathrm{Nb}_{4 x}\right] \mathrm{NbO}_{3} \\
& \text { i.e., } \\
& 6 \mathrm{Li}_{\mathrm{Li}}+3 \mathrm{O}_{\mathrm{O}}+\mathrm{Nb}_{\mathrm{Nb}}=3(1-x) \mathrm{Li}_{2} \mathrm{O}+(x) 4 \mathrm{~V}_{\mathrm{Li}}^{\prime}+(x) \mathrm{Nb}_{\mathrm{Li}}^{\cdots},
\end{aligned}
$$

where, $\mathrm{Li}_{\mathrm{Li}}, \mathrm{Nb}_{\mathrm{Nb}}$ and $\mathrm{O}_{\mathrm{O}}$ represent lithium, niobium and oxygen atoms at their regular sites, respectively; $\mathrm{Nb}_{\mathrm{L} \text { - }}^{\cdots}$ denotes $\mathrm{Nb}$ ion with four unshared electrons at lithium regular site and $\square$ is the vacancy. Similarly in $\mathrm{Li}_{2} \mathrm{O}$ rich side, $\mathrm{Nb}$-vacancies would be expected according to the relation

$$
\mathrm{Li}_{1-5 x} \mathrm{Nb}_{5 x 4}\left[\mathrm{Nb}_{1-4 x} \square_{4 x}\right] \mathrm{O}_{3}
$$

The decrease in density of the LN crystal (table 1) with the decrease in $\mathrm{Nb}$ content rules out the charge compensation mechanism via oxygen vacancies. Holms and Minford (1987) have also unambiguously rejected the oxygen vacancy mechanism on the basis of accurate density $(\rho)$ measurements. Lerner et al (1968), on the basis of results obtained towards density of LN (increase in $\rho$ with $\mathrm{Li}_{2} \mathrm{O}$ losses), have proposed that unit cells of $\mathrm{LN}$ are lost in proper stoichiometric ratio, as the $\mathrm{Li}_{2} \mathrm{O}$ content decreases according to reaction (5).

Table 1. Melt and crystal compositions, $\% \mathrm{Li}^{+}$vacancy and density of $\mathrm{LN}$ single crystal with different $\mathrm{Li} / \mathrm{Nb}$ ratio.

\begin{tabular}{lccccc}
\hline $\begin{array}{l}\text { Starting } \\
\text { composition } \\
\left(\mathrm{Li}_{2} \mathrm{O} / \mathrm{Nb}_{2} \mathrm{O}_{5}\right)\end{array}$ & $\begin{array}{c}\text { Melt } \\
\text { composition } \\
(\mathrm{Li} / \mathrm{Nb})_{m}\end{array}$ & $\begin{array}{c}\text { Crystal } \\
\text { composition } \\
(\mathrm{Li} / \mathrm{Nb})_{c}\end{array}$ & $\begin{array}{c}\text { Actual } \\
\text { composition } \\
\left(\mathrm{Li}_{2} \mathrm{O} / \mathrm{Nb}_{2} \mathrm{O}_{5}\right)\end{array}$ & $\begin{array}{c}\mathrm{Li}^{+} \\
\text {vacancy } \\
(\%)\end{array}$ & $\begin{array}{c}\text { Density } \\
\left(\mathrm{g} / \mathrm{cm}^{3}\right)\end{array}$ \\
\hline $48.6 / 51.4$ & 0.945 & 0.948 & $48.68 / 51 \cdot 32$ & 4.96 & 4.61 \\
$50 / 50$ & 1.000 & 0.954 & $48 \cdot 83 / 51 \cdot 17$ & 4.39 & 4.55 \\
$52.4 / 47.6$ & 1.100 & 0.969 & $49.22 / 50 \cdot 78$ & 2.39 & 4.48 \\
$54.6 / 45.4$ & 1.200 & 0.980 & $49.5 / 50 \cdot 5$ & $1 \cdot 88$ & 4.45 \\
\hline
\end{tabular}

Table 2. Comparison of thermal expansion coefficients $\alpha_{a}$ and $\alpha_{c}$ for different (Li/Nb) ratio.

\begin{tabular}{lcll}
\hline $\begin{array}{l}\text { Composition } \\
(\mathrm{Li} / \mathrm{Nb})_{m}\end{array}$ & $\begin{array}{c}\alpha_{k i} \\
\left({ }^{\circ} \mathrm{C}\right)\end{array}$ & $\begin{array}{c}\alpha_{c} \\
\left(/^{\circ} \mathrm{C}\right)\end{array}$ & Reference \\
\hline 0.945 & $14.862 \times 10^{-6}$ & $6.544 \times 10^{-6}$ & Present study \\
1.000 & $15.482 \times 10^{-6}$ & $6.012 \times 10^{-6}$ & Present study \\
1.100 & $15.846 \times 10^{-6}$ & $7.012 \times 10^{-6}$ & Present study \\
1.200 & $16.012 \times 10^{-6}$ & $7.362 \times 10^{-6}$ & Present study \\
1.000 & $16.700 \times 10^{-6}$ & $2.000 \times 10^{-6}$ & Abrahams et al (1966) \\
1.000 & $15.000 \times 10^{-6}$ & $7.500 \times 10^{-6}$ & Kim and Smith (1969) \\
1.000 & $15.400 \times 10^{-6}$ & $7.500 \times 10^{-6}$ & Smith and Welsh (1971) \\
\hline
\end{tabular}

$\alpha_{a} \rightarrow$ thermal expansion coefficient along $a$ axis;

$\alpha_{c} \rightarrow$ thermal expansion coefficient along $c$ axis. 
Above results and discussion allow to represent general cation-substituted LN (nonstoichiometric) crystals by

$$
\begin{aligned}
& {\left[\mathrm{Li}_{m 1} \mathrm{Nb}_{n 1} \square_{1-m 1-n 1}\right]\left[\mathrm{Li}_{m 2} \mathrm{Nb}_{m 2} \square_{1-m 2-n 2}\right]} \\
& \times\left[\mathrm{Li}_{m 3} \mathrm{Nb} \square_{1-m 3-n 3}\right] \mathrm{O}_{3} .
\end{aligned}
$$

where, $m_{1}$ and $n_{1}$ are the $\mathrm{Li}$ and $\mathrm{Nb}$ occupancy at $\mathrm{Li}$ site, $m_{2}$ and $n_{2}$ are the occupancies at the ideally empty octahedral sites and $m_{3}, n_{3}$ are the corresponding occupancies at the regular $\mathrm{Nb}$ sites. Equation (5) describes not only the $\mathrm{Li} / \mathrm{Nb}$ vacancy models, but also the $\mathrm{Li}-\mathrm{Nb}$ antisite defects $\left(n_{1}=m_{3}\right)$, and Li-split $\left(m_{2}=0.0\right)$ proposed initially by Shiozaki and Mitsui (1963). Although Lerner et al (1968) have considered antisite defects $(\mathrm{Li}-\mathrm{Nb})$ as very probable, a meticulous investigation by Zotov $e t$ al (1994), combining neutron and X-ray data refinement, could not detect $\mathrm{Li}$ on $\mathrm{Nb}$ sites. Also, $\mathrm{Li}^{+}$at vacant octahedron has not been detected (Zotov et al 1994). The vacancy concentration obtained by taking all the above facts into consideration indicates commensurable increase with increasing $\mathrm{Nb}_{2} \mathrm{O}_{5}$ content (table 1). In nut shell, the lithium vacancy describes the best average structure of $\mathrm{LN}$ crystals under investigation.

The LN crystal being rhombohedral, with symmetric point group $3 m$ and space group $R 3 c$, two coefficients of thermal expansion are expected viz. (i) $\alpha_{a}$, describing the longitudinal effect in X-Y plane i.e. along the $a$ axis and (ii) $\alpha_{c}$, describing the longitudinal effect perpendicular to $\mathrm{X}-\mathrm{Y}$ plane i.e. along the $c$ axis. The experimental thermal expansion coefficients along the $a$ and $c$ axes for different melt compositions, in general, are observed to increase with the increase in the $\mathrm{Li} / \mathrm{Nb}$ ratio (table 2). Particularly, expansion along the $a$ axis is larger than along the $c$ axis, indicating an anisotropy. Furthermore, the data given in table 2 and figure 4 (a continuous line is only a guide) indicates relatively a steeper increase in $\alpha_{a}$ compared to $\alpha_{c}$ with nonstoichiometry. A comparison of the present values of $\alpha_{a}$ and $\alpha_{c}$ with earlier reported values for congruent composition (table 2) reveals a close agreement between the two. However, an observed small deviation in the values of $\alpha_{c}$ is attributed to the difference in evaporation losses during the crystal growth (variation in techniques).

Megaw (1968) during experiments on thermal expansion has made the following important observations: (i) the nearly regular thermal expansion of the $a$ edge of a unit cell is mainly due to tilting of octahedra; the change in size of octahedra plays a minor role in that direction, (ii) the change in edge length of the octahedra is responsible for the change in thermal expansion parameter, as the displacement of $\mathrm{Nb}$ decreases with rise in temperature as does the edge length $s$, (iii) expansion or contraction in crystals is dependent on the rise or fall of a scalar quantity, temperature, (iv) coefficient of

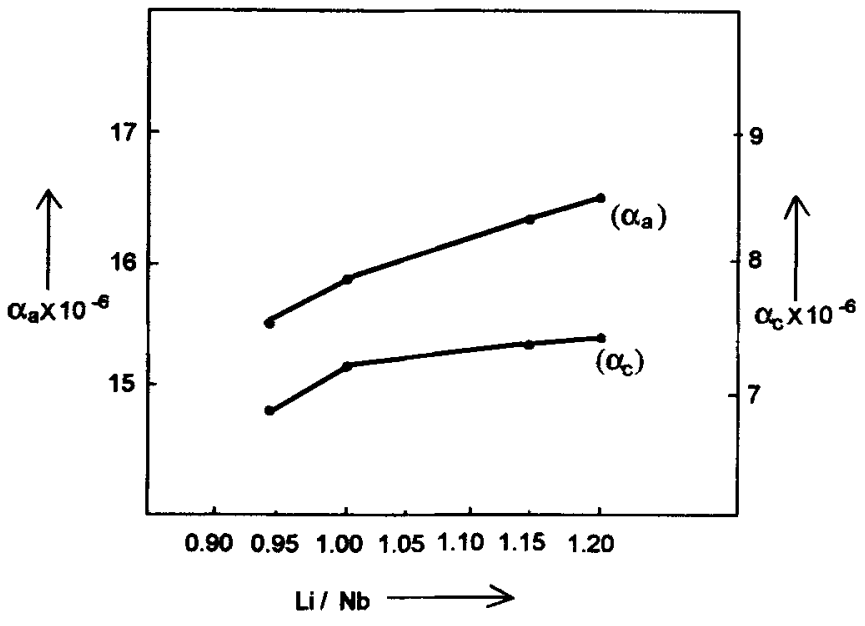

Figure 4. Variation of $\alpha_{u}$ and $\alpha_{c}$ with change in $\mathrm{Li} / \mathrm{Nb}$ stoichiometry.

thermal expansion of a crystal for all systems, except cubic, is dependent on the direction because of anisotropy, and $(v)$ change in edge of a unit cell is more along the $a$ axis than the $c$ axis.

The $\mathrm{Li}^{+}$and $\mathrm{Nb}^{5+}$ in $\mathrm{LN}$ single crystal occupy special positions on the 3-fold axis such that $2 / 3$ of the octahedral sites (oxygen atom at the corners) are occupied by them. Additionally, the cation sequence along the 3-fold axis is ..... Nb Li $\square \mathrm{NbLi} \square \ldots$. . The octahedral tilt, oriented with pair of opposite forces perpendicular to triad axes, displaces the $\mathrm{Nb}$ ions in the direction of triad. Actual displacement, however, depends on the $(\mathrm{Li} / \mathrm{Nb})$ ratio and temperature. The increase in non-stoichiometry causes an increase in octahedral tilt. This in turn, increases the thermal expansion coefficient along $a$ axis. This explains the observed increase in $\alpha_{a}$ with the increase in $\mathrm{Li} / \mathrm{Nb}$ ratio (table 2 ).

\section{Conclusion}

The nonstoichiometry in LN single crystals introduces $\mathrm{Li}^{+}$vacancies in its regular sites, which alters the dynamic and static disorder and can best be explained by experimentally determined values of thermal expansion coefficients.

\section{References}

Abrahams S C, Levinstein H J and Reddy J M 1966 J. Phys. Chem. Solids 271019

Ballman W and Gernand M 1966 Phys. Status Solidi A9 301

Boyd G D, Miller R C, Nassau K, Bond W L and Savage A 1964 Appl. Phys. Lett. 5234

Carruthers J R, Patterson G E, Grasso $\mathbf{M}$ and Bridenbaugh P M 1979 J. Appl. Phys. 421846 
Chen F S 1969 J. Appl. Phys. 403389

Chung W H, Lee J H, Rao J H and Kin J N 1981 J. Korean Phys. Soc. 14162

Deshmukh K G and Singh K $1972 J$. Phys. D5 1686

Geusic J E, Levinstein H J, Rubin J J, Singh S and Van Uitert L G 1968 Appl. Phys. Lett. 11269

Holms R J and Minford W J 1987 Ferroelectrics 7563 and references therein

Kaminov I P and Turner E H 1966 Proc. IEEE 541374

Kim Y S and Smith R T 1969 J. Appl. Phys. 404637

Lemer P, Lagers L and Duman J P 1968 J. Cryst. Growth 3-4 6503

Lovell M, Avery A and Vernon M 1979 Physical properties of materials (London: van Nostrand Reinhold Co. Ltd) p. 115

Megaw H D 1968 Acta Crystallogr. A24 589

Nassau K and Lines M E 1975 J. Appl. Phys. 41533

Nassau K, Levinstein H J and Loiacono G M 1966 J. Phys. Chem. Solids 27983
Ohmachi Y, Sawamoto and Toyoda K 1967 Jap. J. Appl. Phys. 61467

Peterson G E and Carnevale A 1972 J. Chem. Phys. 564848

Polgar K, Jeszenszky L, Raksanyi K and Hartmann E 1979 Acta Phys. Acad. Sci. Hung. 47125

Rauber A 1978 Chem. phys. of lithium niobate, New topics in material science (ed.) E Kaldis (Amsterdam: North Holland)

Reisman A and Holtzberg A 1958 J. Am. Chem. Soc. 806503

Shapiro Z I, Fedulov S A and Venevisex Fiz N 1964 Tverd Tela 6316

Shiozaki Y, and Mitsui T 1963 J. Phys. Chem. Solids 241057

Singh K 1988 Solid State lonics 31139

Singh K and Deshmukh K G 1976 Indian J. Pure \& Appl. Phys. 14823

Singh K and Tikkar B D 1986 J. Phys. 3153

Smith R T and Welsh F S 1971 J. Appl. Phys. 422219

Volk T R 1984 Ferroelectric Lett. 255

Zotov N, Boysen H, Frey F, Metzgen T and Born E 1994 J. Phys. Chem. Solids 55145 